\title{
Review: antidepressants increase remission and clinical improvement in bulimia nervosa
}

Source of funding: not stated.

For correspondence: Dr J Bacaltchuk,

Universidade Federal

de São Paulo, São

Paulo-SP,Brazil.

bacaltc@ibm.net.

Abstract and

commentary also

appear in

Evidence-Based Mental

Health.

Antidepressants v placebo for bulimia nervosa at 6 to 16 weeks*

\begin{tabular}{|c|c|c|c|c|}
\hline Outcomes & Antidepressant type & $\begin{array}{l}\text { Weighted } \\
\text { event rates }\end{array}$ & RBI $(95 \%$ Cl) & NNT (Cl) \\
\hline \multirow[t]{4}{*}{ Remission } & All types & $20 \% \vee 7.9 \%$ & $105 \%$ (32 to 219$)$ & $9(6$ to 16$)$ \\
\hline & TCAs & $14 \%$ v $9.1 \%$ & $136 \%(-4$ to 476$)$ & $\begin{array}{l}\text { Not } \\
\text { significant }\end{array}$ \\
\hline & MAOIs & $25 \% \vee 6.3 \%$ & $229 \%$ (-22 to 1289$)$ & $\begin{array}{l}\text { Not } \\
\text { significant }\end{array}$ \\
\hline & Other antidepressants & $15 \%$ v $0 \%$ & $664 \%$ (-1 to 5773$)$ & 7 (4 to 27$)$ \\
\hline \multirow[t]{5}{*}{$\begin{array}{l}\text { Clinical } \\
\text { improvement }\end{array}$} & All types & $64 \%$ v 33\% & $84 \%$ (38 to 145$)$ & 4 (3 to 5$)$ \\
\hline & TCAs & $77 \%$ v $17 \%$ & $294 \%$ (59 to 872 ) & 2 (2 to 3$)$ \\
\hline & SSRIs & $58 \% v 38 \%$ & $51 \%(26$ to 81$)$ & 5 (4 to 9$)$ \\
\hline & Other antidepressants & $44 \% \vee 8.2 \%$ & $321 \%$ (74 to 919$)$ & $3(3$ to 5$)$ \\
\hline & & & $\operatorname{RRR}(\mathrm{Cl})$ & NNT \\
\hline \multirow[t]{6}{*}{ Drop outs } & SSRIS & $34 \%$ v $40 \%$ & $18 \%$ (1 to 32$)$ & $\begin{array}{l}\text { Not } \\
\text { significant }\end{array}$ \\
\hline & Other antidepressants & $30 \% \vee 32 \%$ & $6 \%(-83$ to 52$)$ & $\begin{array}{l}\text { Not } \\
\text { significant }\end{array}$ \\
\hline & & & RRI (Cl) & NNH \\
\hline & All types & $34 \%$ v $31 \%$ & $3 \%(-20$ to 32$)$ & $\begin{array}{l}\text { Not } \\
\text { significant }\end{array}$ \\
\hline & TCAs & $26 \% \vee 11 \%$ & $93 \%(15$ to 225$)$ & $\begin{array}{l}\text { Not } \\
\text { significant }\end{array}$ \\
\hline & MAOls & $34 \%$ v $29 \%$ & $20 \%(-33$ to 113$)$ & $\begin{array}{l}\text { Not } \\
\text { significant }\end{array}$ \\
\hline
\end{tabular}

${ }^{*} \mathrm{MAOIS}=$ monoamine oxidase inhibitors; SSRIs = selective serotonin reuptake inhibitors; $\mathrm{TCAs}=$ tricyclic antidepressants. Other abbreviations defined in glossary; RBI, RRR, RRI, NNT, NNH, and Cl calculated from data in article. 2001;(4):CD003931 (latest version 19 Aug 2001).

\section{Data sources}

Studies were identified by searching Medline; EMBASE/ Excerpta Medica; LILACS; PsycLIT; SCISEARCH; the Cochrane Depression, Anxiety, and Neurosis Group Database of Trials; the Cochrane Controlled Trials Regis-

Bacaltchuk J, Hay P. Antidepressants versus placebo for people with bulimia nervosa. Cochrane Database Syst Rev

\section{QUESTION: In patients with bulimia nervosa (BN), are antidepressants effective for increasing remission and clinical improvement?}

ter; Clinical Evidence; and reference lists. The International Journal of Eating Disorders was also hand searched, and authors and pharmaceutical companies were contacted.

\section{Study selection}

Studies were selected if they were randomised controlled trials (RCTs) that compared any antidepressant with placebo for $\geqslant 4$ weeks in patients with BN. RCTs were excluded if patients had binge-eating or purging-type anorexia nervosa or binge-eating disorder.

\section{Data extraction}

2 reviewers assessed the quality of RCTs and extracted data on patients, study characteristics, drug regimens, and outcomes (including remission $[100 \%$ reduction in binge or purge episodes], clinical improvement [ $\geqslant 50 \%$ reduction in binge or purge episodes], and drop outs).

\section{Main results}

16 RCTs (1300 patients) met the selection criteria. Any antidepressant was better than placebo for increasing remission at a mean follow up of 8 weeks ( 8 RCTs) and clinical improvement at a mean follow up of 9 weeks ( 8 RCTs) (table). Groups did not differ for dropout rates (14 RCTs) (table)

\section{Conclusion}

In patients with bulimia nervosa, antidepressants are effective in the short term for increasing remission and clinical improvement rates.

\section{COMMENTARY}

The reviews by Bacaltchuk et al are laudable for the rigour of the data analyses, but they rightly generate more questions than answers. Bacaltchuk and Hay have comprehensively reviewed 16 published RCTs of antidepressant treatments for BN. Although modest effectiveness is shown, high dropout rates among patients limit the clinical application of these data, and the authors comment on the need for more studies of tolerability and cost effectiveness. The studies included were generally of short duration in young adult women who did not have any substantial psychiatric comorbid conditions. The results therefore cannot be generalised to the substantial minority of bulimic patients with comorbid "multi-impulsive" personality characteristics ${ }^{1}$ or substance abuse or to adolescents.

Pharmacological treatment trials of $\mathrm{BN}$ are dominated by the reported reduction in bulimic symptoms, but clinicians and their patients are more interested in remission of symptoms. The emphasis of this review on remission is therefore of greater clinical application than the emphasis of its sources. The review discusses the limitations of outcome measures and is right to conclude that the use of antidepressants as sole treatment "does not seem sufficient to effectively treat these patients".

Bacaltchuk et al review a scant number of studies comparing combined antidepressant medication and psychotherapy with each treatment alone. In clinical practice, cognitive behavioural therapy (CBT), which is limited by its availability, is generally regarded as the treatment of choice for BN, with antidepressant medication as an adjunct. This review supports that approach by using restricted data from fairly small studies. However, the clinical risk associated with a pharmacological approach to BN seems to be a higher dropout rate than with CBT and, again, the results cannot necessarily be generalised beyond young adult women who have no substantial comorbid illness.

The UK Department of Health's National Service Framework for Mental Health has stressed the importance of managing such eating disorders as BN in primary care, ${ }^{2}$ noting that "antidepressants can reduce purging and bingeing whether or not the person is also depressed". Although this statement is true in the short term, it would seem an optimistic reading of the literature. Prescription of antidepressants may appear to be the easiest route in a primary care setting, but the clinical implication of Bacaltchuk $e t$ als review is that the easiest route may not be the most effective, cost effective, or acceptable for clinicians and their patients. continued on next page 


\section{Review: psychological treatment is as effective as antidepressants for bulimia nervosa, but a combination is best}

Bacaltchuk J, Hay P, Trefiglio R. Antidepressants versus psychological treatments and their combination for bulimia
nervosa. Cochrane Database Syst Rev 2001;(4):CD003385 (latest version 13 Aug 2001).

QUESTION: In patients with bulimia nervosa (BN), are antidepressants as effective as psychological treatment (PT) for increasing remission and clinical improvement rates? Is a combination of antidepressants and PT better than each intervention alone?

\section{Data sources}

Studies were identified by searching Medline; EMBASE/ Excerpta Medica; LILACS; PsycLIT; SCISEARCH; the Cochrane Depression, Anxiety, and Neurosis Group Database of Trials; the Cochrane Controlled Trials Register; Clinical Evidence; and reference lists. The International Journal of Eating Disorders and book chapters on $\mathrm{BN}$ were also hand searched, and authors and pharmaceutical companies were contacted.

\section{Study selection}

Studies were selected if they were randomised controlled trials (RCTs) that compared antidepressants with PT in patients with BN. Studies were excluded if patients had binge-eating or purging-type anorexia nervosa or binge-eating disorder.

\section{Data extraction}

2 reviewers assessed the quality of studies and extracted data on patients, study characteristics, interventions, and outcomes (including remission $[100 \%$ reduction in binge or purge episodes], clinical improvement $[\geqslant 50 \%$ reduction in binge or purge episodes], and drop outs).

\section{Main results}

5 RCTs (237 patients) compared antidepressants with PT. Groups did not differ significantly for remission (5 RCTs); only 1 RCT reported on clinical improvement. More drop outs occurred in the antidepressant group than in the PT group (4 RCTs) (table). 5 RCTs (247 patients) compared combination and single interventions.

Antidepressants versus combination: more patients in the combination group than in the antidepressant alone group had remission (4 RCTs) (table); only 1 RCT reported on clinical improvement. Groups did not differ for dropout rates (4 RCTs).
$P T$ versus combination: more patients in the combination group than in the PT alone group had remission (6 RCTs); fewer patients in the PT alone group than in the combination group dropped out (6 RCTs) (table). Groups did not differ for clinical improvement (2 RCTs) (table).

\section{Conclusions}

In patients with bulimia nervosa, psychological treatment and antidepressants do not differ in remission rates, but dropout rates are lower with psychological treatment. A combination of antidepressants and psychological treatment is best for increasing remission.
Source of funding: not
stated.

For correspondence: $D r$ J Bacaltchuk,

Universidade Federal de São Paulo, São Paulo-SP,Brazil. bacaltc@ibm.net.

\section{Abstract and}

commentary also appear in

Evidence-Based Mental Health.

Antidepressants $(A D)$ v psychological treatment $(P T)$ for bulimia nervosa*

\begin{tabular}{|c|c|c|c|c|}
\hline Outcomes & Comparisons & $\begin{array}{l}\text { Weighted event } \\
\text { rates }\end{array}$ & RBI (95\% CI) & NNT (Cl) \\
\hline \multirow[t]{4}{*}{ Remission } & PT $v$ AD & $41 \%$ v $20 \%$ & $63 \%(-14$ to 210$)$ & NS \\
\hline & $A D+P T v A D$ & $47 \%$ v $23 \%$ & $79 \%(11$ to 188$)$ & 5 (3 to 21$)$ \\
\hline & $\mathrm{PT}+\mathrm{AD} v \mathrm{PT}$ & $50 \% \vee 36 \%$ & $30 \%$ (1 to 68$)$ & 8 (5 to 37$)$ \\
\hline & & & RBR (CI) & NNH \\
\hline \multirow[t]{2}{*}{$\begin{array}{l}\text { Clinical } \\
\text { improvement }\end{array}$} & $\mathrm{PT}+\mathrm{AD} v \mathrm{PT}$ & $46 \%$ v $52 \%$ & $8 \%(-70$ to 50$)$ & NS \\
\hline & & & $\operatorname{RRR}(\mathrm{Cl})$ & NNT (Cl) \\
\hline \multirow[t]{4}{*}{ Drop outs } & PT v AD & $18 \%$ v $41 \%$ & $54 \%$ (9 to 76 ) & 5 (3 to 10$)$ \\
\hline & $A D+P T \vee A D$ & $35 \%$ v $41 \%$ & $16 \%(-45$ to 51$)$ & NS \\
\hline & & & RRI (Cl) & NNH (Cl) \\
\hline & $\mathrm{PT}+\mathrm{AD} v \mathrm{PT}$ & $26 \% \vee 16 \%$ & $74 \%(14$ to 167$)$ & 10 (6 to 40$)$ \\
\hline
\end{tabular}

${ }^{*} \mathrm{NS}=$ not significant; RBR = relative benefit reduction. Other abbreviations defined in glossary; RBI, RBR, RRR, $\mathrm{RRI}, \mathrm{NNT}, \mathrm{NNH}$, and $\mathrm{Cl}$ calculated from data in article. Follow up ranged from 5 to 24 weeks.

\section{COMMENTARY_continued from previous page}

However, in the busy world of primary care, the treatment of BN will continue to be driven by available resources. CBT for BN is generally preferred by the family doctor when specialists with such training are available. But the Royal College of Psychiatrists, in collaboration with the Consumers' Association, has recently reported the dearth of specialist eating disorder services beyond southeastern England. Thus, in the more likely scenario of limited eating disorder services, use of antidepressant medication may seem more attractive. These 2 reviews agree with that approach and suggest that antidepressant medication will produce positive short term results; however, $\mathrm{BN}$ is not a short term illness. Relapse prevention deserves greater scrutiny for patients with $\mathrm{BN}$ and anorexia nervosa, and longer term follow up studies should drive the next generation of treatment intervention studies.

Regarding treatment of $\mathrm{BN}$ in particular, a pressing need exists for longer term studies examining relapse rates, health economics, and comparisons of classes of antidepressants for treatment concordance.

1 Lacey JH. Inpatient treatment of multi-impulsive bulimia nervosa. In: Brownell KD, Fairburn CG, editors. Eating disorders and obesity: a comprehensive handbook. New York: Guilford Press, 1995:361-8.

2 A national service framework for mental health modern standards and service models. London: Department of Health, 1999.

3 Eating disorders in the UK: policies for service development and training. London: Royal College of Psychiatrists, August 2001. http://www.rcpsych.ac.uk/publications/cr/ council/cr87.pdf. 